Twinning, sex ratio, birthweight, and parity among Bantu in a Tanganyika sample, 209

Ulcer, duodenal, survey of, using N.H.S. general practice records, 177

-, peptic, epidemiology of, $* 46$

Unemployment in males with psychiatric symptoms, 191

United Kingdom, human brucellosis in, 90

United States of America, geographical variations in mortality from congenital malformations in, 13

- - , mortality from arteriosclerotic heart disease in, compared with South Africa, 33
Vital registration records, automatic linkage of, with medical records, 185

Wales, South, coronary disease, in 1953

*Waterhouse, J. A. H., and Cross, K. W.: Cancer prevalence in the Midland region, 45

*WING, J. K., and BROWN, G. W.: Relationships between social and clinical change in a mental hospital, 47

Worker, psychiatric social, role of, in employment of psychiatric cases, 193

WYLliE, J. M.: see PIKE, M. C., etc., 172

\title{
CORRIGENDUM
}

\section{Efficiency of Mental Hospitals}

Dr. E. S. Stern, co-author of the above (Brit. J. prev. soc. Med., (1963), 17, 111), should have been described as Medical Superintendent, the Central Hospital, Warwick.

On p. 111, col. 2, the formula should read

$$
B=\frac{2 f}{2 d+e-e^{\prime}} \simeq \frac{f}{d}
$$

On p. 112, col. 2, in the caption to Fig. 1, the dates should be 1853-1960. 